\title{
GRANDES ESPERANÇAS EM UM MUNDO DE INJUSTIÇAS: INTERFACES ENTRE AMARTYA SEN E CHARLES DICKENS
}

\author{
GREAT EXPECTATIONS IN A WORLD OF INJUSTICE: INTERFACES BETWEEN \\ AMARTYA SEN AND CHARLES DICKENS
}

\author{
Pedro Augusto Gravatá Nicoli
}

\begin{abstract}
RESUMO: o presente ensaio promove uma aproximação entre a Ideia de Justiça de Amartya Sen e a obra-prima Grandes Esperanças, do romancista inglês Charles Dickens, publicada em 1860, lançando luz sobre aproximações e contrapontos entre a teoria de Sen e a vivência dos personagens de Dickens. Essa correlação parte da epígrafe da obra de Sen, que evoca as injustiças sentidas pelo protagonista Pip, de Grandes Esperanças, na abertura de seu projeto de justiça. Para tanto, as dimensões estruturantes da teoria da justiça de Sen serão revisitadas, como um projeto concreto de remoção de injustiças, nas linhas da argumentação racional e da teoria da escolha social, em contraponto a teorias transcendentes. Por sua vez, o universo do menino Pip, de Grandes Esperanças, revelará o complexo caminho desde a inocência infantil à obsessão e esnobismo, com esperanças e frustrações construídas no cenário da Inglaterra vitoriana, de mazelas profundas da pobreza e desigualdade legadas pela Revolução Industrial. Dickens, nesse sentido, é ao mesmo tempo um crítico ácido de seu tempo, engajando-se na transformação social, e um mestre na exploração da dinâmica psíquica das relações humanas. Assim é que se aproximam os autores pelo retrato pungente da injustiça, a demandar a máxima e imediata remoção. Afastam-se, talvez, no convite à reflexão abstrata do justo e do ético em si, bem como do peso dado às instituições. De todo modo, pensar a justiça nesse espaço compartilhado, em que o poder evocativo e o alcance comunicativo das ideias sejam expandidos, coloca-se como exercício enriquecedor em todos os sentidos.
\end{abstract}

PALAVRAS-CHAVE: Amartya Sen. Charles Dickens. Direito e Literatura. Injustiça. Teoria da Justiça.

ABSTRACT: This paper promotes a comparison between Amartya Sen's Idea of Justice and the masterpiece Great Expectations of English novelist Charles Dickens, published in 1860, shedding light on proximities and counterpoints between the theory of Sen and the experience of Dickens' characters. This correlation departs from the epigraph of Sen's work, which evokes the injustices experienced by the protagonist Pip in Great Expectations, opening a project of justice. For this purpose, the structural dimensions of Sen's theory of justice will be revisited, as a concrete project for removal of injustices on the lines of rational argumentation and the theory of social choice, opposed to transcendent theories. In its turn, the universe of the boy Pip of Great Expectations reveals the complex path from childhood innocence to obsession and snobbery, with hopes and frustrations built in the backdrop of Victorian England, with the deep wound of poverty and inequality as a legacy of Industrial Revolution. Dickens, in this sense, is at once a sharp critic of his time, engaging in social transformation, and a master in exploring the psychological dynamics of human relationships. Hence, the authors become close on the poignant portrayal of injustice, demanding maximum

\footnotetext{
* Graduado em Direito pela Universidade Federal de Minas Gerais (2006). Mestre (2010) e doutorando em Direito pela mesma Universidade. Bolsista da Capes.E-mail: pedrogravata@gmail.com Revista da Faculdade de Direito - UFPR, Curitiba, vol. 60, n. 1, jan./abr. 2015, p. 39-59.
} 
and immediate removal. They are perhaps apart on the invitation to reflect abstractly on justice and ethics in itself, as well as on the weight given to the institutions. In any case, to reflect over justice in this shared space, in which the evocative power and communicative reach of ideas are expanded, becomes an enriching exercise in all senses.

KEYWORDS: Amartya Sen. Charles Dickens. Injustice. Law and Literature. Theory of Justice.

O filósofo do Direito que se aventura pelas margens da literatura é como Colombo a colocar o pé no Novo Mundo, ignorando a natureza exata de sua descoberta ilha ou continente?

François Ost ${ }^{1}$

\section{UMA APROXIMAÇÃO DECLARADA: SEN ADMIRADOR DE DICKENS}

"No pequeno mundo onde as crianças levam sua existência não há nada que seja percebido e sentido tão precisamente quanto a injustiça"² (DICKENS, 1860, apud SEN, 2011a). É com esta citação do escritor inglês Charles Dickens ${ }^{3}$, em sua obra-prima Grandes Esperanças, que Amartya $\mathrm{Sen}^{4}$ inaugura sua célebre reflexão sobre a justiça. Evocando um sentido intuitivo, expresso na mais inocente das visões - a de uma criança de seis anos de idade - Sen passará a refletir sobre os direcionamentos básicos de uma ideia de justiça, relembrando a evidência plena de sua antítese: a sempre sensível injustiça, que se revela de maneira direta e concreta.

Em sua $A$ ideia de justiça, Amartya Sen apresenta uma reflexão sobre a justiça que se coloca como projeto de eliminação de injustiças no mundo, nas matrizes de uma teoria da decisão social. Abre franca crítica à justiça no plano da completa idealidade e assume uma perspectiva racionalista - alternativa, contudo, ao contratualismo e ao institucionalismo transcendente da vertente iluminista mais destacada - compreendendo as exigências dessa justiça, as formas de argumentação racional, os materiais da justiça e a democracia.

O livro Grandes Esperanças de Charles Dickens, por sua vez, foi publicado pela primeira vez em 1860 e retrata a jornada do órfão Philip Pirrip (autodenominado Pip), que

\footnotetext{
${ }^{1}$ No original: "The philosopher of the law who ventures onto the shores of literature is like Columbus setting foot in the New World, ignorant of the exact nature of his discovery - island or continent?" (OST, 2006, p. 19).

${ }^{2}$ A passagem de Dickens (2012, p. 58) no original inglês: "In the little world in which children have their existence whosoever brings them up, there is nothing so finely perceived and so finely felt, as injustice".

${ }^{3}$ Charles Dickens nasceu em 7 de fevereiro de 1812 em Portsmouth, Inglaterra. Começou sua carreira literária como jornalista. Ao longo de sua vida escreveu diversas obras consagradas, como Oliver Twist, A Christmas Carol, Nicholas Nickleby, David Copperfield, A Tale of Two Cities e Great Expectations. Morreu em 1870, como um dos escritores de língua inglesa mais significativos de todos os tempos.

${ }^{4}$ Amartya Sen nasceu em 3 de novembro de 1933, em Santiniketan, atual Bangladesh. Após a Partição de 1947, emigrou com a família para a Índia, onde estudou antes de se doutorar em economia pelo Trinity College, em Cambridge, Reino Unido. Sen recebeu em 1998 o prêmio Nobel de economia por seu trabalho sobre a economia do bem-estar social. É professor da Universidade de Harvard.
}

Revista da Faculdade de Direito - UFPR, Curitiba, vol. 60, n. 1, jan./abr. 2015, p. 39-59. 
deixa uma vida de pobreza e simplicidade no campo para, ao ser surpreendentemente agraciado por uma fortuna a ele doada anonimamente, tornar-se um gentleman na Londres do século XIX. O enredo é construído essencialmente no entorno dos dilemas morais gerados no caminho de Pip, lidando diretamente com a dimensão da justiça das ações e decisões tomadas pelo protagonista ao longo de seu processo de transformação. Além disso, promove uma recomposição bastante contundente das injustiças e mazelas da Inglaterra vitoriana, desde a crueldade da execução penal, com as chamadas presigangas (navios-presídios; do inglês press-gang) e a pobreza do interior, até os contrastes de uma Londres deteriorada por uma violentíssima desigualdade e pelos resultados sociais da Revolução Industrial em curso.

É nesse quadro que se revela toda a força de uma alusão de abertura: a citação de Dickens, para além de um mero adereço ou preciosismo estético, simboliza muito do que se passará na obra de Sen, que destaca sempre a "importância das vidas, experiência e realizações humanas" (SEN, 2011a, p. 48) para a compreensão da justiça. Dando um sentido visceral à sua abordagem, Sen aposta na plataforma reflexiva das realizações e vidas concretas, para além de quadros organizacionais. E destaca, ainda, o papel das liberdades reais de escolha entre diferentes tipos de vida possíveis. Essa inclinação conceitual, enfim, em muito se amolda aos dilemas que Pip, na vivência de suas grandes esperanças, enfrenta na obra de Dickens.

Resta, então, avaliar se essa primeira aproximação declarada se manterá no cotejo entre a realidade narrada na ficção por Dickens e o projeto de justiça de Amartya Sen. No presente ensaio, então, procurar-se-á trabalhar, de alguma forma, as perguntas formuladas por Winfried Fluck (2003, p. 19): "Podem textos ficcionais, como romances, peças teatrais ou filmes oferecer contribuições significativas para a questão do que constitui a justiça? De que maneira eles podem autorizar demandas de justiça?"5.

Diante de uma realidade ficcional marcada pelas múltiplas faces da injustiça em Grandes Esperanças, parece existir um interessante campo para a avaliação da própria consistência e dos eventuais problemas na teorização da justiça de Amartya Sen. Se remover injustiças e consolidar uma matriz de capacidades para compreender aquilo que é justiça (e realizá-la) é o que pretende Sen, a trajetória e ações de personagens como Pip, o casal Gargery, Miss Havisham, Estella, Magwitch, Jaggers e Orlick podem nos colocar diante de diversas reflexões que, no mínimo, expandem os horizontes da reflexão jurídico-filosófica. Isso porque, como pontua François Ost (2006, p. 4):

\footnotetext{
${ }^{5}$ No original: "Can fictional texts such as novels, plays, or films offer meaningful contributions to the question of what constitutes justice? In what way can they authorize claims for justice?’. (Tradução nossa). Revista da Faculdade de Direito - UFPR, Curitiba, vol. 60, n. 1, jan./abr. 2015, p. 39-59.
} 
Enquanto o Direito codifica a realidade, instituindo-a em uma rede estreita de qualificações acordadas e marcando-a por todo um sistema de restrições e proibições, a literatura, por outro lado, libera as possibilidades em seu coração, suspende nossas certezas, despertando em si mesma adormecidas energias, balançando identidades e convenções e trazendo-nos a essas encruzilhadas onde tudo pode começar de novo ${ }^{6}$.

$\mathrm{Na}$ suspensão das certezas e na liberdade criativa de um dos maiores nomes da literatura de língua inglesa, uma teoria de justiça, inflexão filosófica invariavelmente ambiciosa por aproximar-se do humano em essência, poderá encontrar sua prova de fogo. Não será, decerto, o plano ficcional um instrumento para a avaliação formal ou mesmo global de uma teoria como a de Sen. Mas é certo que a acuidade e intensidade das visões de uma mente como a de Dickens podem inspirar e provocar a exploração dos mais recônditos domínios humanos, espaços onde o justo e o injusto expressam-se em toda sua complexidade.

\section{O PROJETO DE JUSTIÇA DE AMARTYA SEN}

A ideia de justiça de Sen, pela contundência de sua abordagem e pelo seu compromisso com os desafios concretos e com a realização material em primeiro plano, coloca-se, talvez, como um projeto: "o que nos move [...] não é a compreensão de que o mundo é privado de uma justiça completa - coisa que poucos de nós esperamos -, mas a de que a nossa volta existem injustiças claramente remediáveis que queremos eliminar" (SEN, 2011a, p. 9).

O autor trabalha no senso das injustiças manifestas, tentando, a todo o momento, criticar a tentativa de alcance da perfeição e dela escapar, focando-se, em vez disso, na máxima remoção das injustiças. A injustiça é, portanto, o ponto de partida para sua reflexão crítica. Não significa, contudo, que o autor propõe um relativismo individualista em sua ideia de justiça, uma vez que, para Sen, "compreender o mundo nunca é uma questão de apenas registrar nossas percepções imediatas. Compreensão inevitavelmente envolve o uso da razão" (SEN, 2011a, p. 10). Em suma, não parece haver dúvida de que a dimensão intuitiva do senso de justiça nos move, mas esta deve ser sempre analisada criticamente. Sen apresenta, então, as seguintes perguntas: pode existir objetividade na construção do conceito de justiça? Independência e imparcialidade em relação aos próprios interesses? Fuga do paroquialismo?

\footnotetext{
${ }^{6}$ No original: "Whereas the law codifies reality, instituting it in a narrow network of agreed-upon qualifications and marking it out by a whole system of constraints and prohibitions, literature, on the other hand, liberates the possibilities in its heart, suspends our certainties, arousing in itself slumbering energies, shaking up identities and conventions and bringing us to those crossroads where everything can begin anew". (Tradução nossa).

Revista da Faculdade de Direito - UFPR, Curitiba, vol. 60, n. 1, jan./abr. 2015, p. 39-59.
} 
As primeiras duas partes da obra $A$ ideia de justiça trazem as considerações fundantes, respostas possíveis a tais perguntas.

Abre-se, aqui, a possibilidade de uma primeira contraposição estrutural à visão do autor. Sen, ao longo da obra, reitera a necessidade de remoção progressiva da injustiça e da aplicação de mecanismos racionais de base comparativa para fazê-lo. A pergunta que parece persistir é: como refletir sobre a remoção e melhoria sem apresentar o que seria perfeito na concepção de justiça? A própria formulação de um projeto de remoção parece partir do pressuposto de uma justiça perfeita, ainda que ela seja concreta, multivocal e nunca completa. Uma justiça possível, como a que parece querer Sen, é irremediavelmente "plena de idealidades",

E mais. Como aponta Boot (2012, p. 8), "se Sen estiver certo, isso implica que as teorias da justiça como as desenvolvidas por John Rawls - que Sen chama de teorias 'transcendentais' de justiça 'perfeita' - são, em grande parte, supérfluas”. E, como se verá adiante, o paralelo com a vida de personagens como Pip e situações intricadas como as por ele vividas podem dificultar substancialmente essa marcha de remoção de injustiças em bases comparativas.

O próprio Sen (2011a, p. 8), aliás, em alguns momentos antecipa essa potencial crítica, afirmando que "pode-se mostrar que é totalmente incorreta a suposição de que esse exercício comparativo não pode ser feito sem que primeiro sejam identificadas as exigências da justiça perfeita". Fala, para tanto, de uma pluralidade na construção do justo, que se faria multivocal e conviveria com argumentos contrapostos, razoáveis e, enfim, justos. Note-se que Sen busca se afastar, sempre, de um relativismo cínico, reforçando a base da racionalidade argumentativa.

Contudo, ainda que plural, a razão de Sen pode ser lida como um espaço de idealidade e seu projeto de reduzir progressivamente as injustiças detectadas segue na mesma direção. E a crítica é, então, expandida por Boot (2012, p. 20), ganhando corpo e pertinência no sentido da impossibilidade de dissociação analítica entre justiça perfeita e justiça comparável, considerando que "princípios integrados de justiça são necessários não apenas para possibilitar a identificação da justiça 'perfeita', mas também para poder comparar adequadamente os estados sociais imperfeitos" $"$.

\footnotetext{
${ }^{7}$ Essa expressão é resultado da interpretação de Habermas por Bernardo Fernandes e Flávio Pedron (2007). Cf., ainda, OLIVEIRA (2002, p. 37).

${ }^{8}$ No original: 'Integrated principles of justice are needed not only to be able to identify 'perfect' justice, but also to be able to adequately compare imperfect social states" (Tradução nossa). 
É nesse ponto que a discordância com John Rawls se revela nodal para a obra de Sen. Rawls constrói seu conceito de justiça como equidade, entendida como uma igualdade primordial, em estado de imparcialidade, na qual os princípios de justiça podem ser unanimemente escolhidos. Esses princípios se desdobrariam, então, em instituições justas e na estrutura da sociedade (nos estágios constitucional e legislativo $)^{9}$. Essa abordagem rawlsiana de justiça como equidade, como ideia fundamental anterior e subjacente à justiça, é profundamente revista por Sen (2011a), justamente com base na pluralidade de interesses não tendenciosos e imparciais formando a justiça. Sen aponta, ainda, uma mudança de rota no pensamento de Rawls em escritos posteriores à sua teoria da justiça, sobretudo na percepção da dificuldade dos acordos unânimes quanto ao justo.

Soma-se, aqui, crítica direta ao radicalismo da liberdade como primeiro princípio; a necessidade de análise do comportamento real em detrimento de estruturas hipotéticas; o contratualismo social e a crença em comportamentos razoáveis dos indivíduos depois de sua pactuação; a vinculação à comunidade política que decorra do contrato social (redundando na perda da dimensão global) e a idealidade de todo o sistema. Nesse conjunto de contraposições a Rawls, Sen alimenta um compromisso de leitura realista das instituições e quer, além de tudo, instituições que promovam justiça, em vez de instituições que sejam em si justas. Para ele, "perguntar como as coisas estão indo e se elas podem ser melhoradas é um elemento constante e imprescindível na busca da justiça" (SEN, 2011a, p. 117).

Por outro lado, Sen aproxima-se significativamente de Rawls pela relevância que os dois autores dão à equidade, à objetividade, à razoabilidade e à liberdade como conceitos centrais de suas concepções sobre o justo. Além disso, a materialidade processual da equidade e da liberdade no plano social é dado central para ambos.

De todo modo, a crítica a Rawls serve para expor algo que o próprio Sen entende como axial em sua obra. Reafirmando sempre sua crença na racionalidade, o autor deixa claro que em vez de se filiar a uma matriz contratualista, ou de um institucionalismo transcendental (que terminaria discutindo as questões em uma perspectiva das instituições em si), partilharia de uma tradição alternativa do próprio Iluminismo, esteada na obra do Marquês de Condorcet, pela "teoria da escolha social" (SEN, 2011a, p. 18). Sen (2011a, p. 38) insiste em uma distância significativa entre essas duas vertentes, sendo a segunda baseada em uma “comparação focada em realizações”. Essa é essencialmente a raiz de sua crítica a Rawls (e também a Dworkin e Nozick), que, segundo ele, seriam institucionalistas transcendentais.

\footnotetext{
${ }^{9}$ Cf., nesse sentido, RAWLS (2008, p. 13 et seq.). 
Em resumo, Sen entende que instituições perfeitamente justas seriam o eixo das teorias da justiça modernas, criticando-as pela factibilidade e redundância, em contraste à sua ideia de justiça focada em realizações. Expande, com base nisso, a crítica à possibilidade de dois princípios de justiça igualmente sérios e imparciais. Para sustentar sua visão, apresenta o exemplo das três crianças e uma flauta, no qual cada uma das três tem uma razão sólida para ter a flauta: uma sabe tocá-la, outra é pobre e não tem brinquedos e a terceira fez a flauta. Utilitaristas, igualitaristas econômicos, trabalhistas ou libertários responderão de modos diferentes e de maneira justificada. Tal alegoria, para Sen (2011a, p. 46), sepultaria a utilidade de uma reflexão sobre arranjos de plena justiça: "se uma teoria da justiça deve orientar a escolha arrazoada de políticas, estratégias ou instituições, então a identificação dos arranjos sociais inteiramente justos não é necessária nem suficiente". Propõe, então, a substituição da resposta única por um "acordo baseado na argumentação racional pública sobre rankings de alternativas que podem ser realizadas" (SEN, 2011a, p. 47). É esta abordagem comparativa como base da teoria da escolha social, ligada originalmente à técnica e à matemática, que Sen propõe trazer para a sua teoria da justiça.

\section{JUSTIÇA GLOBAL E UNIVERSALISMO}

Sen (2011a) mostra-se, ainda, um crédulo na ideia de justiça global, que vise resolver problemas desta proporção, como a patente de medicamentos contra a AIDS ou a guerra contra a fome. Supera, assim, a esfera das instituições do Estado soberano, criticando Hobbes, Thomas Nagel e, mais uma vez, Ralws. Entende que a eliminação de arranjos injustos, em escala, melhoraria a justiça global. E, no sentido de um projeto global, Sen (2013) também escreve especificamente sobre outros temas-chave, como a proteção jurídica ao trabalho humano. Diz, em texto publicado pela Organização Internacional do Trabalho, que "o mundo em vias de globalização da economia, com todas as suas oportunidades e todos os seus problemas, exige uma compreensão também global da importância que reveste o trabalho decente e os numerosos desafios que isso implica na vida econômica, política e social" (SEN, 2013, p. 104) ${ }^{10}$.

Uma de suas marcas nesse projeto de justiça global é uma proposta de abertura multicultural. Por diversas vezes Sen (2011a) se vale, por exemplo, de narrativas da cultura indiana para situar suas reflexões. Isso não implica, contudo, a adoção de uma postura

${ }^{10}$ No original: "El mundo en vías de universalización económica, con todas sus oportunidades y todos sus problemas, exige una comprensión también mundial de la importancia que reviste el trabajo decente y de las múltiples exigencias que entraña éste en las esferas económica, política y social" (Tradução nossa).

Revista da Faculdade de Direito - UFPR, Curitiba, vol. 60, n. 1, jan./abr. 2015, p. 39-59. 
relativista, uma vez que a franca defesa e promoção da justiça global funcionam como nortes permanentes. Essa abordagem é desenhada em detalhes na visão de Sen - por exemplo, quanto à democracia. O autor expande, em outro ensaio (SEN, 1999), o papel instrumental da democracia e sua função construtiva de valores, que alimentariam uma importância intrínseca. Assim, a condição cultural não deveria excluir (nem mesmo limitar excessivamente) as escolhas concretas do tempo presente, no cumprimento do papel final de uma democracia contemporânea, afirmada, em última instância, como um valor universal. Finalmente, o autor sustenta, em colocação bastante direta, não haver "uma dissonância radical entre o pensamento 'ocidental' e o 'oriental' (ou, genericamente, não ocidental)” (SEN, 2011a, p. 16), afirmando que as ideias de justiça e bem aparecem em diversas culturas de maneira semelhante.

Nesse ponto, abre-se um flanco para uma crítica na linha da profundidade das diferenças culturais e das projeções que podem ser feitas de parte a parte. É certo que as próprias origens e experiências de Sen, além de seu rigor, autorizam-no a discorrer criticamente sobre as aproximações em torno das noções de justiça na Índia e no Ocidente. De todo modo, a contundência de suas conclusões conclama o resgate de um possível e já sólido contraponto de leituras.

E o melhor dos exemplos nesta direção talvez venha da China. Herdeira de uma tradição multimilenar, a civilização chinesa revela uma dinâmica de sentidos e referências na experiência social distanciada das categorias com as quais a civilização ocidental ordenou, ao longo dos séculos, a vida em sociedade ${ }^{11}$. Noções como liberdade, política e indivíduo, por exemplo, têm dimensões muito próprias em uma e outra civilização. Algumas, aliás, claramente estruturantes na mundivisão ocidental, são utilizadas modernamente em transposições linguísticas sem correspondentes no chinês tradicional. Wagner (2004, p. 135) salienta a importação no século XX de "quase todos os termos-chave que organizam a experiência, como história, sociedade, estado, filosofia, literatura, ciência, experiência, prática ou teoria" ${ }^{\prime 2}$. Assim é que uma visão como a do sinólogo e filósofo francês François Julien (2008, p. 134) poderia entrar em rota de colisão com a posição de Sen, ao apontar como distorções interpretativas recorrentes:

\footnotetext{
${ }^{11}$ Não se pleiteia a existência de uma homogeneidade conceitual absoluta na matriz das civilizações. Contudo, a permanência de certos macroelementos transversais, dos quais se pode identificar um conteúdo referencial e uma linha de transformação histórica ou de variantes espaciais determinadas, viabiliza a categorização civilizacional e a reflexão em torno de conceitos estruturantes, como a justiça. Sobre o conceito de civilização, cf. RAMOS (2012).

${ }^{12}$ No original: "Nearly all the key terms that organize experience, such as history, society, state, philosophy, literature, science, experience, practice or theory" (Tradução nossa).

Revista da Faculdade de Direito - UFPR, Curitiba, vol. 60, n. 1, jan./abr. 2015, p. 39-59.
} 
Quando, numa tradução francesa do chinês clássico, nós encontramos os termos 'verdade', 'ser', 'tempo', 'ideal', 'vontade' etc., como é normalmente o caso, não é que o termo chinês a traduzir seja evidente, mas que uma assimilação já foi realizada, para melhor passar o sentido estrangeiro para nossa língua, fazendo-nos já entrar no quadro mental de suas possibilidades e de nossas expectativas teóricas: gerando assim em boa conta, mas indevidamente, a ilusão de universalidade ${ }^{13}$.

Assim, parece certo concluir que Sen assume uma inclinação universalista, ainda que mitigada, permeável às variações culturais. É ele mesmo quem se declara legatário das linhas de argumentação racionais de um iluminismo europeu, dizendo, contudo, que promoverá o uso de ideias não ocidentais ${ }^{14}$. É inevitável, assim, perguntar-se: como se utilizar de ideias não ocidentais numa matriz iluminista? A razão iluminista, crítica, é uma construção cultural do ocidente e, universalizante que é, tende a promover uma leitura que pode distorcer os institutos para amoldá-los aos preceitos da razão. De todo modo, no seu projeto de justiça, Sen alimenta a ideia de uma identidade ética humana no sentido de uma justiça universal de bases racionais, a se materializar como plano concreto e prático, sem uma transcendência institucional a ela associada.

\section{EXIGÊNCIAS DA JUSTIÇA: RAZÃO, ARGUMENTAÇÃO E ESCOLHA SOCIAL}

Para compreender quais as exigências da justiça, Sen (2011a, p. 70) coloca-se criticamente diante de uma espinhosa pergunta, central para sua tese: "por que deveríamos aceitar que a razão tenha de ser o árbitro final das crenças éticas?" Sen parece não se satisfazer com uma fundamentação em si e aponta para caminhos que podem chegar a resultados melhores do que simples observações, ainda que rigorosas. Ao mesmo tempo, reafirma a objetividade da argumentação racional como algo a ser sempre perseguido. Esta objetividade poderia ser identificada e aplicada a problemas reais, de forma imparcial, no contexto da argumentação pública irrestrita, democrática, processo do qual derivaria, finalmente, a justiça social. O que diferencia a teoria de Sen é o distanciamento da ideia de um monólito de princípios que sobrevivem à análise objetiva. Diz, então, defender a

\footnotetext{
${ }^{13}$ No original: "quand, dans une traduction française du chinois classique, nous rencontrons les termes de 'vérité', d'être', de 'temps', d' 'idéal', de 'volonté', etc., comme c'est si souvent le cas, ce n'est pas que le terme chinois soit d'évidence à traduire ainsi, mais qu'une assimilation déjà s'est accomplie, pour mieux couler le sens étranger dans notre langue, nous faisant déjà rentrer dans le cadre mental de ses possibilités et de nos attendus théoriques : générant ainsi à bon compte, mais indûment, l'illusion d'universalité" (Tradução nossa).

${ }^{14}$ Fala, por exemplo, em niti e nyaya, dois conceitos da literatura sânscrita que significam justiça. Niti estaria associado a um arranjo institucional e uma correção de comportamento. Nyaya seria o conceito de justiça realizada. Além disso, apresenta o conceito de matsyanyaya, ou "justiça do mundo dos peixes", no qual vigora a lei do mais forte (SEN, 2011a, p. 50 et seq.).

Revista da Faculdade de Direito - UFPR, Curitiba, vol. 60, n. 1, jan./abr. 2015, p. 39-59.
} 
possibilidade da permanência simultânea de posições contrárias, desde que submetidas ao crivo de sua racionalidade social, argumentativa e procedimental.

Assim é que, ao estruturar sua ideia de justiça no entorno da escolha social, Sen incorpora a ideia de construção dialógica do justo, nas matrizes de uma razão prática e da argumentação. Como visto, a justiça emerge da resposta a perguntas comparativas e da garantia de uma multivocidade em escala global, e não como desdobramento teórico de uma razoabilidade derivada de um contrato social hipotético.

A teoria da escolha social apareceu na Revolução Francesa, pelas mãos de matemáticos como Borda e Condorcet, que estudavam "o método de agregação de juízos individuais de um grupo de diferentes pessoas" (SEN, 2011a, p. 122), com vistas a afastar instabilidades e arbitrariedades nos processos de escolha. A teoria foi reavivada, em meados do século XX, por Kenneth Arrow (1951) - autor com quem Sen dialoga intensamente -, que se voltou às dificuldades das decisões coletivas, estudando as condições de um procedimento de decisão social considerado adequado. $\mathrm{O}$ foco, para Arrow, era a ampliação da base de informações da teoria da escolha social.

Nessa linha, Sen (2011a) aprofunda sua crítica e passa a questionar a indispensabilidade de uma dimensão transcendental da teoria da justiça, prestigiando a abordagem comparativa como meio de resolução de problemas. Afirma que teorias transcendentais podem se colocar como um "manual completo", distante, contudo, dos debates reais sobre a justiça, para, em conclusão bastante direta, afirmar que a ideia transcendente de algo justo é desnecessária. E resume, numa figuração bastante marcante, afirmando que a pergunta "o que é uma sociedade justa?" não seria um bom ponto de partida e não precisaria ser respondida por uma teoria da justiça (SEN, 2011a, p. 136).

Alternativamente, Sen trabalha a teoria da escolha social como estrutura argumentativa da justiça, entendendo que ela contribui para focalizar as comparações, reconhecer a pluralidade de princípios, permitir o reexame, viabilizar soluções parciais e interpretações diversas, enfatizar a argumentação precisa, especificando o papel da argumentação pública. Aliás, para Sen (2004), a própria ideia de direitos humanos é fundada nessas bases, em relação estruturante com a argumentação, forma de manutenção de viabilidade e universalidade desses direitos.

Nesse sentido, pontua que "transcender as limitações de nossas perspectivas posicionais é importante na filosofia moral e política, e na teoria do direito" (SEN, 2011a, p. 187). Nesse processo, é preciso levar em consideração as compreensões posicionais para se chegar à objetividade. Pensar a objetividade ética a partir de um lugar genérico, hipotético ou 
indeterminado seria por demais lacunoso. Em sua perspectiva relacional, uma abordagem "posicionalmente não tendenciosa" (SEN, 2011a, p. 200) é necessária para a teoria da justiça, afastando-se o efeito social de obscurecimento que poderá advir do posicionamento.

Assim, as ilusões posicionais devem ser superadas pelo alargamento da base informacional, em um regime comparativo, e, mais uma vez, não com vistas a uma independência total e ideal. Sen (2011a, p. 205-6) critica, ainda, o sentido de identidade próxima, apontando que "nenhuma teoria da justiça de hoje pode ignorar o mundo inteiro [...] ainda que haja tentativas de convencer-nos de que é apenas a nossos vizinhos locais que devemos alguma ajuda para superar a injustiça”.

Vale, ainda, destacar que na reflexão de suas exigências à justiça Sen decanta um conceito próprio de razão, consolidando seu afastamento de estruturas apriorísticas de alcance largo e puramente teórico. Para o autor (2011a, p. 228):

A racionalidade é primariamente uma questão de basear - explícita ou
implicitamente - nossas escolhas no raciocínio que podemos sustentar
reflexivamente, e exige que nossas escolhas, assim como nossas ações e objetivos,
valores e prioridades, possam sobreviver ao nosso próprio exame crítico, seriamente
realizado.

Diante disso, a ideia de realizações como desdobramentos de uma estrutura justa e perfeita se mostra incompatível com o pensamento de Sen. É a partir daí que o autor consolida a operacionalidade de sua reflexão, em torno de uma abordagem de capacidades, como "a oportunidade de realizar combinações valiosas de funções humanas: o que uma pessoa é capaz de fazer ou ser" (SEN, 2004, p. 332) ${ }^{15}$. Esse aspecto processual da teorização de Sen se relaciona intimamente com sua visão realizadora de justiça. Nas palavras dele, "a abordagem da capacidade está particularmente interessada em transferir esse foco sobre os meios para a oportunidade de satisfazer os fins e a liberdade substantiva para realizar esses fins arrazoados" (SEN, 2011a, p. 268) ${ }^{16}$.

Há, em suma, uma contribuição substantiva de Sen para a reflexão da justiça, em sua visão comparativa e realizadora, centrada na eliminação das injustiças sensíveis, e não no plano das puras idealidades. Essa é uma visão que pode encontrar rico substrato reflexivo nas injustiças retratadas por Dickens em Grandes Esperanças, nas matrizes propostas por Ost (2006, p. 6):

\footnotetext{
${ }^{15}$ No original: "the opportunity to achieve valuable combinations of human functionings: what a person is able to do or be" (Tradução nossa).

${ }^{16}$ As críticas à abordagem de capacidades e, de modo geral, ao liberalismo igualitário, assumem formas diversas. Pode-se argumentar, por exemplo, que essas linhas fazem afastar as políticas sociais da garantia dos bens primários, e seu sucesso passaria a se pautar pelo assegurar de uma capacidade de concorrência. A felicidade, assim, seria um desdobramento dessa garantia de simples capacidades. Cf. MENDONÇA, 2012.

Revista da Faculdade de Direito - UFPR, Curitiba, vol. 60, n. 1, jan./abr. 2015, p. 39-59.
} 
Em vez de um diálogo de surdo-mudo entre, de um lado, um sistema jurídico que é codificado, institucionalizado, forte na eficácia e racionalidade, e, de outro lado, uma literatura que institucionaliza, com ciúmes de sua ficcionalidade e sua irracionalidade, eu vejo uma dialética emergente, em que cada parte vai reconhecerse como compartilhada, complexa e em evolução ${ }^{17}$.

\section{O RETRATO DA INJUSTIÇA EM GRANDES ESPERANÇAS E A ABORDAGEM DA JUSTIÇA DE SEN: APROXIMAÇÕES E CONTRAPONTOS}

A concreção do projeto de justiça de Amartya Sen e as mazelas das desigualdades sociais no retrato de Grandes Esperanças podem se relacionar de formas muito variadas. De modo geral, as aproximações mais evidentes se desenham nas diversas passagens da obra de Dickens em que se vê uma interação direta entre o destino dos personagens e o meio social em que estão inseridos. Os resultados concretos das injustiças sociais se manifestam, assim, nas próprias escolhas e mesmo nas frustrações das esperanças construídas em um terreno marcado pelas desigualdades. Ao mesmo tempo, a complexidade psíquica dos personagens de Dickens e a face menos evidente da justiça nos comportamentos humanos em situações extremas podem levantar contrapontos possíveis, em que as noções de objetividade e o desiderato último de remoção de injustiças sejam postos à prova. As múltiplas nuanças dos personagens de Dickens - profundamente humanos - convidam, reiteradamente, a uma reflexão ética que talvez revele alguma vulnerabilidade na teoria de Sen.

Quanto às aproximações, a influência concreta de condicionamentos sociais ocupa um papel central no pensamento de Sen. Tome-se, por exemplo, as considerações dele sobre a fome e seus efeitos na esfera ética, ao pontuar que "a compulsão de adquirir alimentos em quantidade suficiente pode obrigar as pessoas vulneráveis a fazer coisas das quais elas se ressentem, e pode fazê-las aceitar vidas com pouca liberdade" (SEN, 1989, p. 769) ${ }^{18}$. A centralidade de uma pauta como esta revela a definitiva permeabilidade da teoria de Sen às contingências reais na ação humana e, por fim, na concepção do justo.

Também em Grandes Esperanças diversos condicionamentos sociais - como a fome, o abandono, a posição da mulher em uma sociedade opressora, o trabalho, a imposição de pena cruel - reproduzem um ciclo de injustiças e alimentam ações individuais distorcidas e moralmente questionáveis. Deve-se atentar, de antemão, para interpretações inadequadas de Grandes Esperanças como uma obra determinista, uma vez que os personagens desdobram-se

\footnotetext{
${ }^{17}$ No original: "instead of a deaf-mute dialogue between, on the one hand, a legal system that is codified, institutionalized, strong in effectiveness and rationality, and, on the other hand, a literature that institutionalizes, jealous of its fictionality and its irrationality, I see an emerging dialectic, in which each party will acknowledge itself as shared, complex, and evolving" (Tradução nossa).

${ }^{18}$ No original: "The compulsion to acquire enough food may force vulnerable people to do things which they resent doing, and may make them accept lives with little freedom" (Tradução nossa).

Revista da Faculdade de Direito - UFPR, Curitiba, vol. 60, n. 1, jan./abr. 2015, p. 39-59.
} 
de maneira profundamente complexa em termos de consciência e escolhas (HAGAN, 1954, p. 172-3). Makati (2008) enfatiza, então, a maestria de Dickens diante de um estranhamento psíquico que decorre das condições em que a existência em sociedade se materializa. É justamente nesta tensão entre as responsabilidades e o condicionamento que o autor mostra sua genialidade criativa e sensibilidade social, estimulando a complexificação de uma reflexão ética de múltiplas camadas, entre indivíduo, grupos e sociedade.

Esta visão aguda de Dickens a respeito da relação meio-agente aparece muito fortemente no tema da família e da infância, largamente explorado em obras como Grandes Esperanças. Origens autobiográficas talvez estejam associadas a esta centralidade temática, como aponta Andrews (2012), relembrando que Dickens vinha de família numerosa e a reproduziu ao se tornar pai de dez filhos. Traços de sua história pessoal e do momento sóciopolítico da Revolução Industrial inglesa o tornaram um defensor ferrenho da esfera da infantilidade, em combate a um movimento de parentificação das crianças e à assunção precoce de responsabilidades familiares. Tais elementos são visualizados claramente em Pip, protagonista de Grandes Esperanças, mas também em Oliver Twist e David Cooperfield, obras que apresentam contextos familiares vários.

Diante das influências de modelos perversos em todas as esferas - como o da hiperexploração do trabalho no capitalismo industrial nascente - é possível postular uma interpretação na chave das classes sociais para a obra de Dickens, especialmente Grandes Esperanças. Blackshadow (2006 apud MAKATI, 2008), por exemplo, afirma que Dickens escreveu sobre classes por motivação de suas próprias experiências em sociedade, em postura abertamente simpática ao proletariado, retratado com protagonismo em suas obras. Essa seria, aliás, uma das causas para a enorme popularidade de sua obra entre a classe trabalhadora e sua incorporação definitiva no patrimônio literário da Inglaterra como o relato de uma era.

Esse engajamento de Dickens leva Andrews (2012, p. 297) a concluir que ele (Dickens) mereceria “o título de 'assistente social' honorário por sua incansável promoção de normas sociais de compaixão em relação aos pobres e oprimidos, por defender a reforma da política social e o desenvolvimento de programas comunitários" ${ }^{, 19}$. Nesse sentido, o projeto e a atuação multidimensional de Amartya Sen nas causas da justiça global aproximam-se, mais uma vez, de Dickens, ainda que por diferentes vias.

19 No original: "Dickens deserves to be titled an honorary 'social worker' for his tireless promotion of compassionate social norms with regard to the poor and oppressed, advocacy for social policy reform, and development of community programs" (Tradução nossa). 
As conexões das realidades dos dois autores (a que Sen visa combater em sua ideia de justiça e aquela retratada literariamente por Dickens) podem muito bem ser consolidadas, então, à vista das injustiças do mundo contemporâneo. A atualidade do relato de Dickens é notável. A publicação britânica The Economist (2011, p. 84) chegou, inclusive, a propor uma conexão entre as questões sociais exploradas por Dickens e os dramas do continente africano em nosso tempo, em artigo intitulado Great Expectations: Kenya and Charles Dickens, no qual registra que "as cidades africanas não têm leis vitorianas para pobres ou reformatórios, mas a mistura de crueldade e frêmito lembram Charles Dickens, 200 anos após seu nascimento" 20 . E é justamente o quadro da injustiça contemporânea que alimenta o espírito inovador e comprometido de Sen.

Mas a interface entre os dois autores ultrapassa um compromisso para com a remoção de injustiças, porta primeira de aproximação. Além de iniciar sua ideia de justiça com uma citação textual de Dickens, Sen (2011a) esclarece, ainda, as razões de fundo a justificarem sua referência: as transgressões de comportamentos (e não os defeitos institucionais) estariam na base de sua menção à obra Grandes Esperanças. Cita, então, o comportamento da moça Estella e da irmã de Pip, Mrs. Joe Gargery, como materializações do sentido de injustiça concreta e manifesta por meio do qual construirá toda a sua tese. Estella, em Grandes Esperanças, é a fria e violenta menina da aristocracia por quem Pip se apaixona e de quem, ao longo de toda sua vida, tenta obsessivamente se aproximar, sempre com respostas moralmente reprováveis por parte dela. Mrs. Gargery, por sua vez, é a irmã que criou Pip "com mão de ferro" 21 , que se revela dura em diversas ocasiões, sendo, no imaginário do protagonista, a personificação da rispidez e mesmo da injustiça.

É nesse momento que a literatura parece fornecer dimensões de maior complexidade para a teoria de Sen. A conduta tanto de Estella quanto de Mrs. Gargery - tomadas por Sen como ponto de partida na figuração da injustiça - encontra contextos próprios e razões de ser que dificultam profundamente a avaliação que o jovem Pip, intuitivamente em suas memórias, faz da injustiça sentida. Estella, adotada e criada por uma rica senhora de instabilidade emocional evidente, é construída por ele como um ser sem coração, feito para se vingar dos homens. Mrs. Gargery, por sua vez, leva nos ombros a responsabilidade de criar um irmão e controlar um ambiente doméstico, ao lado de um marido bondoso e generoso, assumindo grandes responsabilidades.

\footnotetext{
${ }^{20}$ No original: "African cities have no Victorian poor laws or workhouses, yet their mix of cruelty and vibrancy smacks of Charles Dickens, 200 years after his birth" (Tradução nossa).

${ }^{21}$ A expressão em inglês é "brought up by hand". Cf. DICKENS (2012, p. 07).

Revista da Faculdade de Direito - UFPR, Curitiba, vol. 60, n. 1, jan./abr. 2015, p. 39-59.
} 
Essa relação sui generis entre os personagens é elucidada por Adina Ciugureanu (2011, p. 360), ao indicar que "o paradigma agressor-vítima nas Grandes Esperanças de Dickens é uma riquíssima fonte de atitudes distintas que os personagens mostram [...]. Curiosamente, cada um dos agressores foi em algum momento uma vítima"22. E a autora prossegue, reportando-se especificamente à visão distorcida que se pode alimentar das personagens femininas do livro de Dickens, sobretudo diante da incapacidade de Pip de se sensibilizar com as frustrações de sua irmã, seja quanto ao casamento (feito à sua custa) ou ao trabalho doméstico incessante e solitário. Aliás, Pip parece não compreender "qualquer uma das mulheres que ele observa [...]; ele tende a percebê-las como criaturas misteriosas e a interpretar mal seus desejos, infortúnios ou tristezas" (CIUGUREANU, 2011, p. 349) ${ }^{23}$.

Ou seja, as próprias atitudes de Mrs. Joe Gargery, irmã de Pip, trazidas à obra de Sen como indisputáveis materializações de uma injustiça sensível e evidente, podem ser recompostas em um paradigma muito mais complexo de relações sociais e psíquicas. E mais: os comportamentos do próprio Pip - enunciado por Sen como centro irradiador de uma percepção das claras injustiças - podem desde o início ser contrastados. Christopher Morris (1987), por exemplo, percebe uma atitude egoística nas ações de Pip, ainda que estas sejam supostamente altruísticas, cobertas pelo verniz da contrição. A solicitude na relação entre Pip e Joe, seu irmão, pode ser um exemplo desse egoísmo oculto. Morris, em essência, discorre sobre uma ambiguidade narrativa de Pip - como narrador e como personagem -, a atingir todas as suas interações. Conclui, então, que o Dickens de Grandes Esperanças, "pelo desdobramento da linguagem e envernizamento de suas contradições, procura sustentar a ilusão de um significado" (MORRIS, 1987, p. 952) ${ }^{24}$.

Nesse contexto, Hagan (1954), em análise clássica da obra, aponta um possível reducionismo em leituras mais afoitas da personalidade de Pip, seja como uma vítima ou como a fonte do mal, indicando que Grandes Esperanças é a história da inquietação de um menino de classe baixa que se torna, sem qualquer esforço, herdeiro de uma fortuna, e o complicado caminho de suas aspirações e transformações, passando-se pela gratidão,

\footnotetext{
${ }^{22}$ No original: "The aggressor-victim paradigm in Dickens's Great Expectations is an exceedingly rich source of distinct attitudes which the characters display [...]. Interestingly, each of the aggressors was sometime a victim" (Tradução nossa).

${ }^{23}$ No original: "Pip does not seem to have the ability to understand his sister's frustrations, such as having married beneath her (her predicament had made this her only marriage option), and having to do the housework herself, without the help of a servant. He does not in fact understand any of the women he observes (Miss Havisham, Estella, Molly, Biddy); he tends to perceive them as mysterious creatures and to misinterpret their desires, misfortunes, or griefs" (Tradução nossa).

${ }^{24}$ No original: "by unfolding language and varnishing its contradictions, seeks to sustain the illusion of a signified" (Tradução nossa). 
compaixão e amor, e até à obsessão, indiferença e esnobismo. O processo de degeneração de Pip (e mesmo de sua possível regeneração) serve ao espírito satírico tão caro a Dickens, incorporando, finalmente um modo de expressar visões sobre a sociedade e sua perversa organização. É nesse quadro que entra uma avaliação multifacetada daquilo que, em essência, seriam o justo e o injusto. A centralidade da ideia de justiça e as torções que ela pode sofrer e irradiar são, assim, cenário básico das relações desenvolvidas. Mais uma vez Hagan (1954, p. 173):

\begin{abstract}
A injustiça é, portanto, o cerne da questão - a injustiça operando sobre e através dos antepassados de Pip e Estella, e continuando seu reinado nos próprios filhos [...]. Uma vez que um ato de injustiça tenha sido cometido, não há como prever até que ponto isso afetará as vidas de gerações ainda por nascer e de pessoas distantes na escala social das vítimas da opressão original ${ }^{25}$.
\end{abstract}

E ainda que este seja, ao primeiro olhar, um espaço de aproximação entre Dickens e Sen - ou seja, ambos têm nas injustiças um ponto de apoio para suas obras -, as origens da injustiça em Dickens parecem irremediavelmente remeter a uma reflexão ontológica e conceitual. Pensar o justo e suas correlações, a origem e os desvios, as falsas externalidades e uma reconstrução plena é essencial a uma análise da justiça no universo de Dickens.

Não há dúvida, como visto, que a construção teórica de Amartya Sen tende a considerar a complexidade específica da avaliação a ser feita, submetida - dentro de padrões de imparcialidade e garantida a pluralidade possível - a uma avaliação racional. Defende, em suma, “a possibilidade de permanência de posições contrárias que sobrevivem simultaneamente e que não podem ser submetidas a uma cirurgia radical que as force para dentro de uma caixa arrumada de exigências completas e apropriadas" (SEN, 2011a, p. 76).

Contudo, de uma maneira geral, a abordagem da justiça de Sen, centrada em realizações, parece ainda considerar que a realidade (e a argumentação racional) revelará sempre a injustiça, ainda que de modo intrincado. Essa realidade, entretanto, pode se apresentar com tal nível de dificuldade que, talvez, a intelecção teórica e substancial sobre a ideia de justiça se coloque como uma real necessidade. Ao concluir que a ideia transcendente de algo justo é desnecessária, Sen (2011a) poderá privar a avaliação da justiça concreta nas situações de uma dimensão importante, o que eventualmente se verificará em Grandes Esperanças.

\footnotetext{
${ }^{25}$ No original: "Injustice is thus at the heart of the matter - injustice working upon and through the elders of Pip and Estella, and continuing its reign in the children themselves [...] Once an act of injustice has been committed, there is no predicting to what extent it will affect the lives of generations yet unborn and of people far removed in the social scale from the victims of the original oppression" (Tradução nossa).

Revista da Faculdade de Direito - UFPR, Curitiba, vol. 60, n. 1, jan./abr. 2015, p. 39-59.
} 
A ideia de eliminar injustiças como projeto pode encontrar na própria história de Pip uma denúncia viva da dificuldade de implementação por meio de uma racionalidade comparativa. Pip, na obra, é um protagonista dúbio, que passa por um processo de desconstrução moral. Desde sua obsessão por Estella, seu abandono do casal que o criou (incluindo sua "injusta" irmã, na sugestão de Sen), até a sua ganância interminável, agregamse aspectos para os quais a dimensão operacional da argumentação racional de Sen poderá não oferecer respostas imediatamente satisfatórias.

Há, ainda, uma outra dimensão no cotejo da obra de Sen com Grandes Esperanças de Dickens que poderá ser objeto de reflexão: a questão institucional. Dickens era reconhecidamente descrente em relação às instituições e, com especial acidez, ao Direito. O mundo jurídico e oficial é reportado como um catalisador de injustiças e de angústias. É o próprio Dickens (1996, p. 621) quem, em Bleak House (A Casa Soturna), dispara: “o único grande princípio do Direito inglês é fazer negócios para si mesmo" ${ }^{26}$. Dickens foi, enfim, um dos maiores críticos da Inglaterra vitoriana e das mazelas da Revolução Industrial no mundo do trabalho, e parecia direcionar grande parte de sua crítica quanto à justiça para as instituições, por mais que os dilemas morais individuais de Pip e dos demais personagens que com ele se relacionam conduzam a estrutura da obra.

Diz Lee (2006, p. 290):

O Direito para Dickens sempre foi um personagem, mais do que um cenário. Ele estava vivo. Poderia ser um monstro amorfo, ou poderia ser simplesmente cego e sem rumo na sua crueldade incidental. Estava por vezes em direção equivocada, às vezes sem direção, mas nunca foi sábio, nunca heroico. [...] Para Dickens, o Direito também foi uma presença de nevoeiro e lama ${ }^{27}$.

A mesma crítica, em certa medida, dirige-se a todos aqueles que operam no mundo jurídico, especialmente em posição de comando. Advogados e juízes, nesse sentido, não raro, são figuras sombrias, que podem corporificar a injustiça, em uma dissociação bem marcada entre a justiça e o mundo das leis. É o caso do poderoso advogado Jaggers de Grandes Esperanças, que administra as questões da herança de Pip e se coloca como uma presença perturbadora e dúbia. Na visão de Hagan (1954), Jaggers é a representação da falha de um sistema repressivo, apropriando-se pessoalmente da esperança da redenção, por conhecer os segredos de um sistema que o torna em si um vértice para onde todos convergem, detentor das

\footnotetext{
${ }^{26}$ No original: "The one great principle of the English law is to make business for itself" (Tradução nossa).

${ }^{27}$ No original: "The law for Dickens was always a character more than a setting. It was alive. It could be an amorphous monster, or it could be simply blind and directionless in its incidental cruelty. It was sometimes wrongheaded, sometimes no headed, but it was never wise, never heroic. [...] For Dickens, the law was also a foggy and muddy presence" (Tradução nossa).
}

Revista da Faculdade de Direito - UFPR, Curitiba, vol. 60, n. 1, jan./abr. 2015, p. 39-59. 
chaves do mistério institucionalizado. "Um olímpico sábio e desiludido, Jaggers comenta como um coro trágico os dois grandes mundos que são o produto e expressão da injustiça social, para cuja existência Pip e outros devem sofrer as consequências terríveis" (HAGAN, 1954, p. 178$)^{28}$.

A denúncia social de Dickens parece, nesse sentido, um tanto mais voltada à imperfeição completa das instituições de seu tempo, pano de fundo para as jornadas morais de seus personagens. Resta saber, então, se o projeto de justiça baseada em realizações proposto por Amartya Sen se colocará de modo a resolver os problemas lançados nas Grandes Esperanças de Dickens, igualmente em sua dimensão institucional.

\section{CONCLUSÃO}

A contribuição de Amartya Sen para uma reflexão contemporânea, compromissada com os problemas do tempo presente, é incontestável. A transformação, no plano ontológico, do pensar em ação - conceituar o justo é, em última análise, maximizar a remoção do injusto - torna a teoria de Sen um instrumento poderoso de transformação social. Não é de se admirar, portanto, que a sua obra de maturidade ( $A$ ideia de justiça), que consolida uma trajetória notável, inicie-se com uma referência direta a um dos autores que mais expressou o agudo incômodo com as injustiças, com a força que a literatura proporciona. Dickens constrói muitas de suas obras sobre as injustiças aparentes e ocultas, e sua reprodução em uma sociedade doente, a padecer de sintomas dos quais o mundo sofre até hoje.

Tomando, então, a linguagem como um espaço compartilhado de construção de sentidos, o exercício de aproximação do universo literário e do jurídico-filosófico pareceu abrir uma nova dimensão a explorar. Uma visão aberta das palavras, como a cultivada pelo próprio Sen, afiança o que se propôs nesse ensaio. Diz o autor (SEN, 2011b, 438) que "as palavras têm significados, muitas vezes mais de um. Muitas palavras também têm poder evocativo e alcance comunicativo que vão muito além do uso restrito destes termos com delimitação profissional bem definida" 29 .

Pensar a justiça nesse espaço compartilhado, em que esse poder evocativo e alcance comunicativo sejam expandidos e explorados em suas múltiplas possibilidades, fornece

\footnotetext{
${ }^{28}$ No original: "A wise and disillusioned Olympian, Jaggers comments like a tragic chorus on the two great worlds that are the product and expression of social injustice, for the existence of which Pip and others must suffer the terrible consequences".

${ }^{29}$ No original: "Words have meanings, often more than one. Many words also have evocative power and communicative reach that go well beyond the restricted use of these terms with well-defined professional delineation" (Tradução nossa).
} 
importante substrato para a realimentação de uma teoria da justiça. E, nesse quadro, a aproximação das ideias é destacada: com toda a licença poética (e talvez jurídico-filosófica) que se pode ter, a aplicação do projeto de justiça de Sen no mundo das Grandes Esperanças do menino Pip talvez pudesse render boas transformações em uma realidade marcada por ganância, exploração e sofrimento.

Ao mesmo tempo, admitindo-se a mão-dupla necessária nesta abertura comunicacional, a realidade dos personagens de Dickens, bem como a sua feroz visão das instituições, talvez devolvam perguntas essenciais ao projeto de Sen. O desafio, aqui, é o de pensar em remoção de injustiças manifestas, quando os protagonistas delas estão enredados em um ciclo vicioso que lhes bestializa, complexifica e torna a distinção entre justo e injusto um exercício dos mais difíceis.

De todo modo, o convite feito por Sen a adentrar o universo do jovem Pip é mais do que justificado. A Inglaterra vitoriana e suas mazelas, além do universo psicológico de personagens memoráveis, colocam o leitor de uma teoria da justiça em um lugar qualificado. Quem viveu, pelas páginas de Dickens, as angústias e infortúnios de uma sociedade em que a injustiça produz diversas vítimas e faz florescer grandes esperanças e, com elas, enormes frustrações, certamente será capaz de compreender a necessidade de se teorizar sobre a justiça e de se remover as injustiças, e a dificuldade enorme que, invariavelmente, a empreitada carregará consigo.

\section{REFERÊNCIAS}

ANDREWS, Arlene Bowers. Charles Dickens, social worker in his time. Social Work. Oxford, v. 57, n. 4, p. 297-307, out. 2012.

ARROW, Kenneth J. Social choice and individual values. Nova Iorque: Wiley, 1951.

BOOT, Martijn. The aim of a theory of justice. Ethical Theory and Moral Practice, n. 15, p. 7-21, 2012.

CIUGUREANU, Adina. The victim-aggressor duality in Great Expectations. Journal of Literature and the History of Ideas, v. 9, n. 2, p. 347-61, jun. 2011.

DICKENS, Charles. Bleak house. Londres: Penguin Classics, 1996.

. Great expectations. New York: Vintage Classics, 2012.

FERNANDES, Bernardo Gonçalves; PEDRON, Flávio Quinaud. Poder Judiciário e (m) crise. Rio de Janeiro: Lumen Juris, 2007. 
FLUCK, Winfried. Fiction and justice. New Literary History. Johns Hopkins University Press, v. 34, n. 1, p. 19-42, 2003.

HAGAN, John H. The poor labyrinth: the theme of social injustice in Dickens's Great Expectations. Nineteenth-Century Fiction, University of California, v. 9, n. 3, p. 169-78, dez. 1954.

JULLIEN, François. De l'Universel, de l'Uniforme, du Commun et du Dialogue entre les Cultures. Paris: Fayard, 2008.

LEE, Randy. Nineteenth Century visions of a twenty-first Century BAR: were Dickens's expectations for lawyers too great? Widener Law Journal, Wilmington, v. 15, p. 283-97, 2006.

MAKATI, Pamela. A critical study of Charles Dickens' representation of the socially disadvantaged. Dissertação de Mestrado. East London: University of Fort Hare, South Africa, 2008, p. 43. 4 Disponível em: $<$ http://ufh.netd.ac.za/bitstream/10353/173/1/Makati\%20thesis.pdf>. Acesso em: 1 set. 2014.

MENDONÇA, Luiz Jorge V. Pessoa de. Políticas sociais e luta de classes: uma crítica a Amartya Sen. Textos \& Contextos, Porto Alegre, v. 11, n. 1, p. 65-73, jan./jul. 2012.

MORRIS, Christopher. The bad faith of Pip's bad faith: deconstructing Great Expectations. English Literature History (ELH). The Johns Hopkins University Press, Baltimore, v. 54, n. 4, p. $941-55,1987$.

OLIVEIRA, Marcelo A. Cattoni de. Direito Constitucional. Belo Horizonte: Mandamentos, 2002.

OST, François. The Law as mirrored in literature. SubStance. Tradução de Roxanne Lapidus. University of Wisconsin Press, n. 109, v. 35, p. 3-19, 2006.

RAMOS, Marcelo Maciel. Os fundamentos éticos da cultura jurídica ocidental: dos gregos aos cristãos. São Paulo: Alameda, 2012.

RAWLS, John. Uma teoria da justiça. Tradução de Jussara Simões. São Paulo: Martins Fontes, 2008.

SEN, Amartya. A ideia de justiça. Tradução de Denise Bottmann e Ricardo Doninelli Mendes. São Paulo: Companhia das Letras, 2011.

\section{Disponível}

Democracy as a universal value. Journal of Democracy, v. 10.3, p. 3-17, 1999. em: 1 set. 2014. $56,2004$.

Elements of a theory of Human Rights. Philosophy \& Public Affairs, 32, n. 4, p. 315Food and freedom. World development, v. 17, n. 6, p. 769-81, 1989. 
2011

Rights, laws and language. Oxford Journal of Legal Studies, v. 31, n. 3, p. 437-53,

. Trabajo y derechos. Revista Internacional del Trabajo. Genebra, OIT, v. 132, p. $94-$ $104,2013$.

THE ECONOMIST. Great expectations; Kenya and Charles Dickens. Londres, 17 dez. 2011, p. 84.

WAGNER, Rudolf G. Notes on the history of the Chinese term for 'labor'. In: LACKNER, Michael, VITTINGHOFF, Natascha (Ed.). Mapping meanings: the field of new learning in late Qing China. Leiden: Brill, 2004.

\title{
GREAT EXPECTATIONS IN A WORLD OF INJUSTICE: INTERFACES BETWEEN AMARTYA SEN AND CHARLES DICKENS
}

\begin{abstract}
This paper promotes a comparison between Amartya Sen's Idea of Justice and the masterpiece Great Expectations of English novelist Charles Dickens, published in 1860, shedding light on proximities and counterpoints between the theory of Sen and the experience of Dickens' characters. This correlation departs from the epigraph of Sen's work, which evokes the injustices experienced by the protagonist Pip in Great Expectations, opening a project of justice. For this purpose, the structural dimensions of Sen's theory of justice will be revisited, as a concrete project for removal of injustices on the lines of rational argumentation and the theory of social choice, opposed to transcendent theories. In its turn, the universe of the boy Pip of Great Expectations reveals the complex path from childhood innocence to obsession and snobbery, with hopes and frustrations built in the backdrop of Victorian England, with the deep wound of poverty and inequality as a legacy of Industrial Revolution. Dickens, in this sense, is at once a sharp critic of his time, engaging in social transformation, and a master in exploring the psychological dynamics of human relationships. Hence, the authors become close on the poignant portrayal of injustice, demanding maximum and immediate removal. They are perhaps apart on the invitation to reflect abstractly on justice and ethics in itself, as well as on the weight given to the institutions. In any case, to reflect over justice in this shared space, in which the evocative power and communicative reach of ideas are expanded, becomes an enriching exercise in all senses.
\end{abstract}

KEYWORDS: Amartya Sen. Charles Dickens. Injustice. Law and Literature. Theory of Justice.

Recebido: 1 de setembro de 2014

Aprovado: 2 de outubro de 2014 